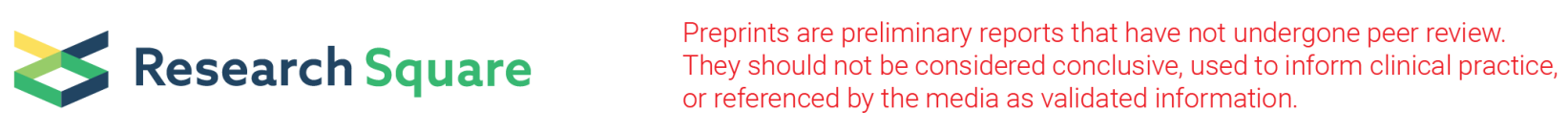

\title{
The moment of communicating the diagnosis of neuromuscular diseases: an integrative review
}

Isabella Araujo Mota Fernandes ( $\nabla$ isabella_mota@yahoo.com.br)

Federal University of Paraíba

Alex Novais Batista

Federal University of Campina Grande

Letícia Pinheiro Melo

Federal University of Campina Grande

Renata Oliveira Almeida Menezes

Federal University of Rio Grande do Norte

Guilhermina Rego

University of Porto

Research Article

Keywords: Truth Disclosure, Neuromuscular Diseases, Physician-Patient Relations, Communication

Posted Date: May 26th, 2021

DOI: https://doi.org/10.21203/rs.3.rs-560153/v1

License: (c) (1) This work is licensed under a Creative Commons Attribution 4.0 International License. Read Full License 


\section{Abstract}

Background: The communication of diagnosis of neuromuscular genetic diseases is a very important moment, because if there is a lack of understanding about the disease, it can limit decision-making, compromising freedom and autonomy of the patients, with several repercussions, such as tendency towards more aggressive therapies in detriment of ensuring better quality of life.

Methods: The guiding question was: did the moment of communicating the diagnosis of neuromuscular diseases value the ethical principles of beneficence, non-maleficence and autonomy? So it was carried out a integrative review with the search for original research articles in the portals Pubmed, Bireme and Scopus between November 2020 and March 2021, whose descriptors were ("Muscular Diseases" OR "Neuromuscular Diseases") AND "Truth Disclosure".

Results: Only one article was found, published in 1983, which had as object of study the diagnosis of Duchenne Muscular Dystrophy. In this study, most patients received the diagnosis without the support of a family member, the time elapsed until the diagnosis was variable, with greater satisfaction for those who had their diagnosis more quickly. Another relevant factor in satisfaction was the scheduling of a return visit to answer questions and discuss the disease management.

Conclusions: The present studies deal with clinical observations, screening methods, complementary exams and treatments, but little is discussed about the communication of the diagnosis and how this moment impacts on the lives of the patients. Thus, the ethical principles of non-maleficence, beneficence and autonomy must also be applied when diagnosing these diseases, in order to ensure a better doctor-patient relationship and better follow-up of the disease.

\section{Background}

The doctor-patient relationship was described by Hippocrates, known as the father of Western medicine, since the beginning of medicine. References to it are found in historical documents dating from the 5th century BC written in lonian Greek $(1,2)$, beyond several translations and adaptations, which emphasize the sovereign importance of the well-being of others, as observed in the Hippocratic oath (3). Technological advances, the discovery of new diseases, the improvement of complementary exams and the emergence of new medications, were part of the changes related to the concepts linked to the doctor-patient relationship throughout history (4).

In this context, the moment of diagnosis is crucial to answer the initial demand of the patient and/or his family and, thus, start a new stage, the treatment. When this diagnosis is related to degenerative, progressive and disabling disease, how it occurs in most neuromuscular diseases, the doctor-patient relationship is even more valuable $(4,5)$.

The clarification of the disease and its proper understanding by the patient and/or his family members are closely related to the ethical principle of autonomy (6). This thought differs from the traditional partenalistic posture characterized by the authoritarianism of priestly medicine, whose conduct would be determined by the physician, the owner of knowledge (3). The lack of understanding about the disease, its evolution, treatment and prognosis limit decisionmaking, compromising freedom and autonomy, with repercussions in several aspects of social, family, work and even the end of life $(7,8)$.

This review aims to discuss studies related to the moment of diagnosis of neuromuscular diseases, initiated in childhood and adolescence. This theme is justified by the importance given by the authors to the process of transmitting the diagnosis of a neurodegenerative disease, impacting not only on the patient's health, but on the whole family, due to the genetic etiology.

As a secondary objective, this study wishes to interpret its findings in the light of the ethical principles of beneficence, non-maleficence and autonomy, aiming to support a future protocol for transmitting the diagnosis of neuromuscular genetic diseases.

\section{Methods}

\section{Leading question and expected outcomes:}

The guiding question that guided the study: The time of communication of the diagnosis of patients with neuromuscular diseases prized by the ethical principles of beneficence, non-maleficence and autonomy? The expected primary outcome is that: the physician beeing concerned about welcoming these patients and their families due to the chronic, progressive and limiting nature of these diseases, prioritizing beneficence and not maleficence at the time of diagnosis. The expected secondary outcome is that the absence of protocols and technical training for this type of diagnosis results in different attitudes that violate the ethics of non-maleficence with damage to patients' autonomy in some proportion of the sample.

\section{Search and selection of articles:}

The search was performed on the Pubmed, Bireme and Scopus portals between November 2020 and March 2021. The descriptors used in the Pubmed search were ("Muscular Diseases" OR "Neuromuscular Diseases") AND "Truth Disclosure", at Bireme were ("Muscular Diseases" OR "Neuromuscular Diseases") and "Truth Disclosure" and Scopus ("Muscular Diseases" OR "Neuromuscular Diseases" AND "Truth Disclosure". There was no restriction related to the year of publication and the filters used were: human studies, English and Portuguese languages. Case reports, letters to the editor and revisions were excluded from this systematic review during the reading of the titles, the abstracts and later by the full reading of the texts. In order to accurately assess the findings of each article, the search aimed at original research articles.

\section{Results}


No randomized study, systematic review, observational or intervention study on this topic was found. A single filtered article dates from 1983 with a focus on the diagnosis of Duchenne Muscular Dystrophy (DMD). There was no mention of the epidemiological profile or socioeconomic data of the selected sample. Other neuromuscular diseases such as other myopathies, spinal muscular atrophy, hereditary polyneuropathies, among others, were not found in the search.

Table 1

Diagnosis of Duchenne muscular dystrophy:

\begin{tabular}{|c|c|c|c|c|c|c|c|c|c|c|c|c|}
\hline $\begin{array}{l}\text { Author, } \\
\text { year }\end{array}$ & $\begin{array}{l}\text { Study } \\
\text { country }\end{array}$ & $\begin{array}{l}\text { Families } \\
\text { Invited } \\
\text { accepted }\end{array}$ & $\begin{array}{l}N \\
(\mathbb{N})\end{array}$ & $\mathrm{T}$ & $\begin{array}{l}\text { Age at } \\
\text { the time } \\
\text { of the } \\
\text { interview }\end{array}$ & $\begin{array}{l}\text { Pre- or } \\
\text { post-test } \\
\text { genetic } \\
\text { counseling }\end{array}$ & $\begin{array}{l}\text { Degree of } \\
\text { satisfaction } \\
\text { (DS) }\end{array}$ & $\begin{array}{l}\text { DS related } \\
\text { factor }\end{array}$ & $\begin{array}{l}\text { Guide- } \\
\text { protocol } \\
\text { questionnaire } \\
\text { described }\end{array}$ & $\begin{array}{l}\text { Diagnosis } \\
\text { given } \\
\text { jointly to } \\
\text { both } \\
\text { parents }\end{array}$ & $\begin{array}{l}\text { Evaluation } \\
\text { form }\end{array}$ & Rand \\
\hline $\begin{array}{l}\text { Firth } \\
\text { MA, } \\
1983\end{array}$ & $\begin{array}{l}\text { Great } \\
\text { Britain }\end{array}$ & $66-53$ & $\begin{array}{l}69 \\
(53)\end{array}$ & $\begin{array}{l}2-5 \\
\text { anos }\end{array}$ & $>4$ anos & $\begin{array}{l}\text { Don't } \\
\text { quote }\end{array}$ & $72 \%$ & $\begin{array}{l}\text { Diagnostic } \\
\text { time }\end{array}$ & Don't quote & 18 (34\%) & $\begin{array}{l}\text { Interview } \\
\text { recorded }\end{array}$ & Don't \\
\hline
\end{tabular}

$\mathrm{N}$ : number of family members interviewed; T: time (years elapsed between the first symptoms and the diagnosis), DS: degree of satisfaction (time of diagnos not satisfied

Due to the fact the sample consisted of only one article, we will expand the discussion with the analysis of studies related to the same disease as the selected article, found during the search and selection of the original research articles. Although the focus of this review be the time of communication the diagnosis in symptomatic in people, who seek answers to clinical symptoms degenerative, it also describes studies that evaluated the time of diagnosis included asymptomatic in screening programs for Duchenne-Becker, in order to enrich the discussion of the topic. All articles selected in this stage were original research.

Table 2

Diagnosis of Duchenne muscular dystrophy screening

\begin{tabular}{|c|c|c|c|c|c|c|c|c|c|c|}
\hline $\begin{array}{l}\text { Author, } \\
\text { year }\end{array}$ & $\begin{array}{l}\text { Study } \\
\text { country }\end{array}$ & $\begin{array}{l}\text { Families } \\
\text { Invited- } \\
\text { accepted }\end{array}$ & $N(\mathbb{\nabla})$ & $\mathrm{T}$ & $\begin{array}{l}\text { Age at } \\
\text { the time } \\
\text { of the } \\
\text { interview }\end{array}$ & $\begin{array}{l}\text { Pre-or } \\
\text { post-test } \\
\text { genetic } \\
\text { counseling }\end{array}$ & $\begin{array}{l}\text { Degree of } \\
\text { satisfaction } \\
\text { (DS) }\end{array}$ & $\begin{array}{l}\text { DS related } \\
\text { factor }\end{array}$ & $\begin{array}{l}\text { Guide- } \\
\text { protocol } \\
\text { questionnaire } \\
\text { described }\end{array}$ & $\begin{array}{l}\text { Diagnos } \\
\text { given } \\
\text { jointly tc } \\
\text { both } \\
\text { parents }\end{array}$ \\
\hline $\begin{array}{l}\text { Parsons } \\
\text { E, } \\
\text { Bradley } \\
\text { D, Clarke } \\
\text { A, } 1996\end{array}$ & Wales & $\begin{array}{l}\text { Don't } \\
\text { quote- } \\
41\end{array}$ & 41 (?) & $\begin{array}{l}\text { Asymptomatic } \\
\text { by screening } \\
\text { until } \\
\text { symptomatic } \\
\text { without } \\
\text { detailing age } \\
\text { range }\end{array}$ & $\begin{array}{l}\text { Protocol } \\
\text { group: } \\
\text { first } \\
\text { weeks of } \\
\text { life. Non- } \\
\text { protocol } \\
\text { group: } \\
\text { does not } \\
\text { cite }\end{array}$ & 25 (61\%) & $\begin{array}{l}\text { S } 22(88 \%) \\
\text { with } \\
\text { protocol } \\
\text { S } 3(19 \%) \\
\text { non- } \\
\text { protocol }\end{array}$ & $\begin{array}{l}\text { Neonatal } \\
\text { screening } \\
\text { protocol }\end{array}$ & Yes & $\begin{array}{l}\text { Don't } \\
\text { quote }\end{array}$ \\
\hline $\begin{array}{l}\text { Järvinen } \\
\text { O et all, } \\
1999\end{array}$ & Helsinki & $\begin{array}{l}\text { Don't } \\
\text { quote - } \\
23\end{array}$ & $\begin{array}{l}20 \\
\text { mothers } \\
\text { and } 23 \\
\text { sisters }\end{array}$ & $\begin{array}{l}\text { Sisters | } \\
\text { asymptomatic } \\
\text { cousins }\end{array}$ & 21.7 & $5(22 \%)$ & $\begin{array}{l}\text { S } 76 \% \\
\text { childhood } \\
\text { screening } \\
\text { test }\end{array}$ & $\begin{array}{l}\text { Uncertain } \\
\text { results } \\
\text { generated } \\
\text { dissatisfaction }\end{array}$ & Yes & $\begin{array}{l}\text { Don't } \\
\text { quote }\end{array}$ \\
\hline $\begin{array}{l}\text { Järvinen } \\
\text { O et all, } \\
2000\end{array}$ & Helsinki & $\begin{array}{l}\text { Don't } \\
\text { quote - } \\
23\end{array}$ & $\begin{array}{l}20 \\
\text { mothers } \\
\text { and } 23 \\
\text { sisters }\end{array}$ & $\begin{array}{l}\text { Sisters | } \\
\text { asymptomatic } \\
\text { cousins }\end{array}$ & 21.7 & $5(22 \%)$ & Don't quote & Don't quote & Yes & $\begin{array}{l}\text { Don't } \\
\text { quote }\end{array}$ \\
\hline $\begin{array}{l}\text { Fraser } \\
\text { HG, } \\
\text { Redmond } \\
\text { RZ, } \\
\text { Scotcher } \\
\text { DF, } 2018\end{array}$ & Manchester & $28-12$ & 12 & $\begin{array}{l}\text { Sisters | } \\
\text { asymptomatic } \\
\text { cousins }\end{array}$ & $\begin{array}{l}18-34 \\
(23.6)\end{array}$ & $4(33 \%)$ & S 4 (33\%) & $\begin{array}{l}\text { Genetic } \\
\text { counseling }\end{array}$ & Yes & $\begin{array}{l}\text { Don't } \\
\text { quote }\end{array}$ \\
\hline $\begin{array}{l}\text { Goldman } \\
\text { A, } \\
\text { Metcalfe } \\
\text { A, } \\
\text { MacLeod } \\
\text { R, } 2018\end{array}$ & Manchester & $15-6$ & $\begin{array}{l}6 \\
\text { mothers } \\
\text { and } 9 \\
\text { sisters }\end{array}$ & $\begin{array}{l}\text { Asymptomatic } \\
\text { sisters }\end{array}$ & $5-18$ & 0 & Don't quote & $\begin{array}{l}\text { Genetic } \\
\text { counseling }\end{array}$ & Yes & $\begin{array}{l}\text { Don't } \\
\text { quote }\end{array}$ \\
\hline
\end{tabular}

$\mathrm{N}$ : number of interviewed family members; T: time (years elapsed between the first symptoms and the diagnosis), DS: degree of satisfaction (time of diagnos

\section{Discussion}

Firth (1983) reports that few parents initially understood the diagnosis of Duchenne's Dystrophy or the understanding was superficial; the majority received the news without the support of their partner and emphasized the anguish of having to inform the family of the diagnostic conclusion. The time of diagnosis was 
variable and parents with faster diagnoses showed greater satisfaction with the way they received the diagnosis compared to those who waited longer for the definition. Another relevant factor in the satisfaction related to the moment of diagnosis was the scheduling of a return to answer questions and discuss managment, since at first the information does not seem to be well absorbed (9).

There was no reference to the perspective of the affected children on the subject, their doubts, their fears and their degree of understanding in general (9). This failure in communicating the diagnosis of genetic diseases to the affected children, due to the emphasis on the management of the disease by health professionals, was described by Metcalfe et al (2008), leaving the parents with this arduous mission (10). Family-centered communication was reported by Parsons (1996) to be beneficial in newborn screening for Duchenne's Dystrophy (11).

Goodwin et al (2015) evaluated the experience of disclosing the diagnosis to children with genetic illness related to some degree of intellectual disability from the perspective of their parents, finding no correlation between the way the diagnosis was received and the way it was transmitted to their children, but only $30 \%$ of the children with Down Syndrome in the sample had their diagnoses revealed (12).

Firth (1983) reports about 2 to 5 years between the onset of the first symptoms and the diagnostic confirmation, but made no mention of the number of previous diagnoses, despite describing the parents' difficulty in accepting a new diagnosis with a more reserved prognosis. There was no report on the number of professionals until diagnostic confirmation, costs related to diagnosis and provider of complementary methods, whether public, private or health care providers (9).

Studies related to the diagnostic screening of patients or patients with the pathogenic variant for DMD or Becker muscular dystrophy (BMD) date from 1996 to 2018, three from the United Kingdom and two from Finland. Only one of them screened newborn boys and four, girls related to people with DMD or BMD (11, $13,14,15,16,17)$. In only one of the studies, more than $50 \%$ of the sample received genetic counseling $(11,14,15,16,17)$.

Järvinen et al (2000) concluded that $65 \%$ of mothers with children with DMD correctly knew the results of their daughters' genetic screening test and suggested seeking genetic counseling only in case of doubt, while Fraser et al (2018) justified the low index of genetic counseling due to the lack of perception of the degree of importance of it by the adolescents. Järvinen et al (2000) also described that $24 \%$ (15) of the adolescents were not informed about the results of their exams by their parents, because they believe that it would not be the right time yet. However, theoretically, in case the genetic information has repercussions on family planning, there should be an encouragement in the dissemination of this information with support and incentive to genetic counseling (12). Given this, shouldn't genetic counseling be mandatory for diagnostic screenings?

Family members, especially mothers, were responsible for communicating the diagnostic results to their carrier daughters in the four articles evaluated, without support, in most cases, from a specialist $(14,15,16,17)$. Järvinen et al $(2000)$ reported that $50 \%$ of mothers had difficulties in transmitting the result of the genetic test to their daughters (15), while about $70 \%$ of the parents of children with Down syndrome did not discuss the diagnosis with their children, according to Goodwin et al (2015) (12). Ablon (2000) describes reports of the moment of diagnosis of neurofibromatosis whose information was received by the mother without the father's participation, without genetic counseling and with superficial information, needing to seek other sources to elucidate her questions (18). Findings consistent with Dennis et al 2017, whose parents with children diagnosed with aneuploidies sought support preferably from research sites, followed by support groups and less than $50 \%$ sought medical support to disclose the diagnosis to their children (19).

The goals pursued in the diagnosis of bad news by doctors are not always expected to the same degree by patients (20) and being able to meet these needs is essential when diagnosing rare diseases. The ability to provide the diagnosis can strengthen or destroy the doctor-patient relationship (21). This review found a single study related to the moment of diagnosis (9), with a scientific gap regarding the experience of the moment of diagnosis in rare genetic diseases, often restricted to a reference center and does not cover neuromuscular diseases (21). Until the diagnosis, the patient and his family carry with them a bag of doubts, anxieties and uncertainties in a family tree full of stories, taboos, prejudices and assumptions that probably have an impact on the lives of these people.

The training of techniques related to the way of transmitting difficult diagnoses has been part of the curriculum of several medical schools (21, 22), however this is not the reality observed in the studies evaluated in the last three decades $(13,14,15,16,17,18)$. While there seems to be an influence of hypocratic paternalistic medicine on current medical conduct, the search for autonomy in decision-making has been a demand of patients (23), with the need for individualization in the doctor-patient relationship.

A systematic review evaluated the time of diagnosis in adults with rare and neurodegenerative diseases, but without genetic transmissibility, such as Amyotrophic Lateral Sclerosis (ALS), Multiple Sclerosis and Parkinson's Disease in European countries, Australia and the United States. Despite an increase in satisfaction regarding the transmission of the diagnosis in more recent articles, there was frequent dissatisfaction with the quality and nature of the information, with the lack of emotional support, content predominantly focused on technique and less on being, in addition to insufficient time to greater doctor-patient interaction at the time of diagnosis (23). Eenennaam et al (2020) developed a guide for communicating prognosis for ALS patients through a systematic review and consensus evaluated by neurologists, rehabilitating doctors, health researchers, patients, family members, an ethics specialist and spiritual counselors (24). Among the topics covered, life expectancy to assist in decision-making and future planning, support to health professionals who clearly and individually help the needs and demands of the patient, and also emphasizes the option of having family members present, as well as, respect for the right to not know details about their illness (24).

How and what information should be given at first? Should affected children or adolescents participate at the time of the consultation? In general how did they receive the information? Do mothers have to be responsible for the tough mission of providing information about a neurodegenerative disease to their children and family members without any support from a specialized professional? What is the purpose of doing genetic screening tests if the screened people do not receive genetic counseling? According to the code of medical ethics, the patient has the right to know information about the diagnosis, 
prognosis, risks and objectives of treatment (art.34) and also prohibits doctors from limiting their right to decide freely about themselves or about their wellbeing (art.31) (25).

A review article published in 2016 by Brighton and Bristowe reports that doctors still face barriers to discuss topics such as end of life, fearing a negative impact on patients' lives, due to insecurity about the evolution of the disease and their technical ability to transmit bad news, however, the impact of communication is mainly due to honesty, the ability to give hope without delusion, empathy and individualization of each case. These discussions empower the patient, improve the experience of care and the overall quality of life (26). You et al (2015) stated that the greatest difficulty in reaching the goals of palliative care is related to the communication barrier with patients and or their family members regarding the prognosis, understanding of therapeutic limitations and the patient's inability to make decisions (27). Communication failures start at the time of the diagnosis of a progressive and fatal illness, having an impact throughout the patient's life history.

From the above, there is a failure in the principle of non-maleficence that should guide medical practice. Inappropriate communication, exemplified by superficial and generalized information in addition to communication in the absence of a partner or other companion, generates anguish and suffering (28). The diagnosis of an illness is part of the context of the medical act and not of the maternal act, so the absence of emotional and technical support to parents when communicating a neurodegenerative disease to their children is harmful to patients, parents and the family. Legally this poor communication can be interpreted as negligence when the patient and/or family members are not warned about predictable risks (29), while there are no absolute genetic truths and, therefore, genetic counseling works with risk estimation (12).

According to opinion 43 / CNECV / 2004 of the National Council of Ethics for Life Sciences on personal genetic information, "All direct biological relatives can have access to a stored sample, as long as necessary to better understand their own genetic status, but not to know the status of the person to whom the sample belongs". On the other hand, indiscriminate screening and without proper guidance, can lead to anxiety, problems with self-image, stigmatization, disturbance of the family environment, social discrimination, in addition to the violation of individual privacy (32). Thus, all interventions lack free and informed consent, and genetic counseling is a professional imperative (31).

The early detection and screening of neurogenic diseases as they avoid delay in starting treatments and prevent complications, have a positive impact on the ethical principle of beneficence, as well as follow-up consultations when they strengthen the doctor-patient relationship, clarify doubts and guide evolutionarily during the natural history of disease. However, diagnosing without monitoring, without enabling adequate support for a progressive and limiting illness is harmful because of the family's impotence in the medical context. Maleficence can also be seen in the cost related to the screening test which, despite being carried out, did not fulfill the primary objective of individual or family genetic counseling.

The transgression caused by beneficence and non-maleficence, due to poor communication of the diagnosis, goes beyond the principle of autonomy, since without adequate understanding of the context, there is a compromise in care planning, in the decision-making capacity and in case of hospitalization due to the severity of the disease, there is a tendency towards more aggressive therapies at the end of life to the detriment of care that brings more comfort (30).

The focus on parents was evident in the studies described, but in a chronic and neurodegenerative disease, the patients' perspective should be relevant. This paradigm shift in which there is an overvaluation of genetic screening to the detriment of the anguish of the information vacuum has been experienced in the modernity of neurogenic diseases whose main focus is on diagnostic methods and treatment, forming technically excellent professionals, but failing to transmit information. This finding is corroborated by the low frequency of publications on this topic.

\section{Conclusion}

This review demonstrated a shortage in the literature related to communicating the diagnosis of neuromuscular genetic diseases. The researches deal with clinical observations, screening methods, complementary exams and treatments, but little is discussed about the communication of these results and the impact of this moment on the lives of the protagonists of the story, which results in damage to the ethical principles of beneficence, non-maleficence and in the autonomy of those involved.

The development of research aimed at understanding the paths and experiences until the moment of the diagnosis of rare diseases from the perspective of patients and family members is essential to the self-knowledge of this population, and thus, to see the experience of the diagnosis beyond the protocols and conventions written by technicians and theorists, which don't consider the pain of those on the needy side. Experiencing of the diagnosis path ennobles medical knowledge and strengthens the doctor-patient relationship, providing better follow-up of the disease and satisfaction of patients and family members.

\section{Abbreviations}

BC: before christ; DMD: Duchenne Muscular Dystrophy; BMD: Becker Muscular Dystrophy; ALS: Amyotrophic Lateral Sclerosis; CNECV: National Council of Ethics for Life Sciences

\section{Declarations}

\section{Ethics approval and consent to participates}

Not applicable.

\section{Consent for publication}


All authors agreed with the final version of the article and conset for publication

\section{Availability of data and materials}

Not applicable.

\section{Competing interests}

The authors declare that they have no competing interests

\section{Funding}

Not applicable.

\section{Authors' contributions}

This literature review was performed independently and blindly by IAMF and ROAM and revised by ANB and LPM. IAMF, ROAM, ANB and LPM were involved in the analysis and interpretation of the data, supervised and corrected by GR. All authors have read and approved the final manuscript.

Acknowledgments We would like to thank the bioethics service of the Faculty of Medicine of Porto (FMUP) for the support and encouragement of research.

\section{References}

1. Begbie JW. Hippocrates: His Life and Writings. Br Med J. 1872;2(625):674-677. doi:10.1136/bmj.2.625.674

2. Begbie JW. Hippocrates: His Life and Writings. Br Med J. 1872 Dec 28;2(626):709-11. doi: 10.1136/bmj.2.626.709.

3. Breitenfeld T, Jurasic MJ, Breitenfeld D. Hippocrates: the forefather of neurology. Neurol Sci. 2014 Sep;35(9):1349-52. doi: 10.1007/s10072-014-1869-3.

4. Luz PL. Telemedicina e a Relação Médico-Paciente. Bras. Cardiol. 2019; 113(1):100-102. https://doi.org/10.5935/abc.20190117

5. Yaffe MJ, Hovey RB, Rodriguez C. Use of patients' unsolicited correspondence to a family doctor to describe and understand valued components of a doctor-patient relationship: A Hermeneutics approach. BMC Fam Pract. 2019; 20(1):136. https://doi.org/10.1186/s12875-019-1024-6

6. Fritz Z, Schlindwein A, Slowther AM. Patient engagement or information overload: patient and physician views on sharing the medical record in the acute setting. Clin Med (Lond). 2019 Sep;19(5):386-391. doi: 10.7861/clinmed.2019-0079

7. Horton R, Lucassen A. Consent and Autonomy in the Genomics Era. Curr Genet Med Rep. 2019;7(2):85-91. doi: 10.1007/s40142-019-00164-9

8. Simonds AK. Ethics and decision making in end stage lung disease. Thorax. 2003;58(3):272-277. doi:10.1136/thorax.58.3.272

9. Firth MA. Diagnosis of Duchenne muscular dystrophy: experiences of parents of sufferers. Br Med J (Clin Res Ed). 1983;286(6366):700-701. doi:10.1136/bmj.286.6366.700

10. Metcalfe A, Coad J, Plumridge G. et al. Family communication between children and their parents about inherited genetic conditions: a meta-synthesis of the research. Eur J Hum Genet 2008;16:1193-1200. doi: 1038/ejhg.2010.258

11. Parsons E, Bradley D, Clarke A. Disclosure of Duchenne muscular dystrophy after newborn screening. Arch Dis Child. 1996;74(6):550-553. doi:10.1136/adc.74.6.550

12. Goodwin J, Schoch K, Shashi V, Hooper SR, Morad O, Zalevsky M, Gothelf D, Campbell LE. A tale worth telling: the impact of the diagnosis experience on disclosure of genetic disorders. J Intellect Disabil Res. 2015 May;59(5):474-86. doi: 10.1111/jir.12151.

13. Goldman A, Metcalfe A, MacLeod R. The Process of Disclosure: Mothers' Experiences of Communicating X-Linked Carrier Risk Information to At-Risk Daughters. J Genet Couns. 2018 Sep;27(5):1265-1274. doi: 10.1007/s10897-018-0251-7.

14. Järvinen $\mathrm{O}$, Lehesjoki $\mathrm{A}$, Lindlöf $\mathrm{M}$, Uutela $\mathrm{A}$, Kääriäinen $\mathrm{H}$. Carrier testing of children for two X-linked diseases: a retrospective evaluation of experience and satisfaction of subjects and their mothers. Genetic Testing. 1999;3:347-355.

15. Järvinen $\mathrm{O}$, Lehesjoki $A E$, Lindlöf $M$, Uutela A, Kääriäinen $H$. Carrier testing of children for two X-linked diseases: A retrospective study of comprehension of the test results and social and psychological significance of the testing. Pediatrics. 2000 Dec;106(6):1460-5. doi: 10.1542/peds.106.6.1460.

16. Parsons EP, Clarke AJ, Hood K, Lycett E, Bradley DM. Newborn screening for Duchenne muscular dystrophy: a psychosocial study. Arch Dis Child Fetal Neonatal Ed. 2002;86(2):F91-F95. doi:10.1136/fn.86.2.f91

17. Fraser, H.G., Redmond, R.Z. \& Scotcher, D.F. Experiences of Women Who Have Had Carrier Testing for Duchenne Muscular Dystrophy and Becker Muscular Dystrophy During Adolescence. J Genet Counse/27, 1349-1359 (2018). https://doi.org/10.1007/s10897-018-0266-0

18. Ablon J. Parents' responses to their child's diagnosis of neurofibromatosis 1. Am J Med Genet. 2000 Jul 17;93(2):136-42. doi: 10.1002/10968628(20000717)93:2<136::aid-ajmg11>3.0.c0;2-I.

19. Dennis A, Howell S, Cordeiro L, Tartaglia N. "How should I tell my child?" Disclosing the diagnosis of sex chromosome aneuploidies. J Genet Couns. 2015;24(1):88-103. doi:10.1007/s10897-014-9741-4

20. Sweeny K, Shepperd JA, Han PK. The goals of communicating bad news in health care: do physicians and patients agree? Health Expect. 2013 Sep;16(3):230-8. doi: 10.1111/j.1369-7625.2011.00709.x.

21. Kiluk JV, Dessureault S, Quinn G. Teaching medical students how to break bad news with standardized patients. J Cancer Educ. 2012 Jun;27(2):277-80. doi: 10.1007/s13187-012-0312-9. 
22. Wouda JC, van de Wiel HB. The communication competency of medical students, residents and consultants. Patient Educ Couns. 2012 Jan;86(1):57-62. doi: 10.1016/j.pec.2011.03.011.

23. Anestis E, Eccles F, Fletcher I, French M, Simpson J. Giving and receiving a diagnosis of a progressive neurological condition: A scoping review of doctors' and patients' perspectives. Patient Educ Couns. 2020 Sep;103(9):1709-1723. doi: 10.1016/j.pec.2020.03.023.

24. van Eenennaam RM, Kruithof WJ, van Es, MA. et al. Discussing personalized prognosis in amyotrophic lateral sclerosis: development of a communication guide. BMC Neurol 2020; 20, 446. https://doi.org/10.1186/s12883-020-02004-8

25. Código de Ética Médica: Resolução CFM n 2.217, de 27 de setembro de 2018, modificada pelas Resoluções CFM n 2.222/2018 e 2.226/2019 / Conselho Federal de Medicina - Brasília: Conselho Federal de Medicina, 2019.

26. Brighton LJ, Bristowe K. Communication in palliative care: talking about the end of life, before the end of life. Postgrad Med J. 2016 Aug;92(1090):466-70. doi: 10.1136/postgradmedj-2015-133368.

27. You JJ, Downar J, Fowler RA, et al. Barriers to goals of care discussions with seriously ill hospitalized patients and their families: a multicenter survey of clinicians. JAMA Intern Med 2015;175:549-56. doi: 10.1001/jamainternmed.2014.7732.

28. Mendes Á, Paneque M, Sousa L, Clarke A, Sequeiros J. How communication of genetic information within the family is addressed in genetic counselling: a systematic review of research evidence. Eur J Hum Genet. 2016 Mar;24(3):315-25. doi: 10.1038/ejhg.2015.174.

29. Burke T, Rosenbaum S. Law and the Public's Health. Public Health Reports 2005; 120(2), 209-210.

30. Zaros MC, Curtis JR, Silveira MJ, Elmore JG. Opportunity lost: end-of-life discussions in cancer patients who die in the hospital. J Hosp Med. 2013 Jun;8(6):334-40. doi: 10.1002/jhm.1989.

31. Parecer sobre o Projecto de Lei n 28/IX - Informação Genética Pessoal e Informação de Saúde (43/CNECV/2004). CONSELHO NACIONAL DE ÉTICA PARA AS CIÊNCIAS DA VIDA .Presidência do Conselho de Ministros. Posted in April 14, 2004. Accessed in April 21, 2021

https://www.cnecv.pt/pt/pareceres/parecer-sobre-o-projecto-de-lei-no-28-ix-informacao-genetica-pes

32. Nunes R. Gene-Ética, Almedina, Coimbra, 2013.

\section{Figures}

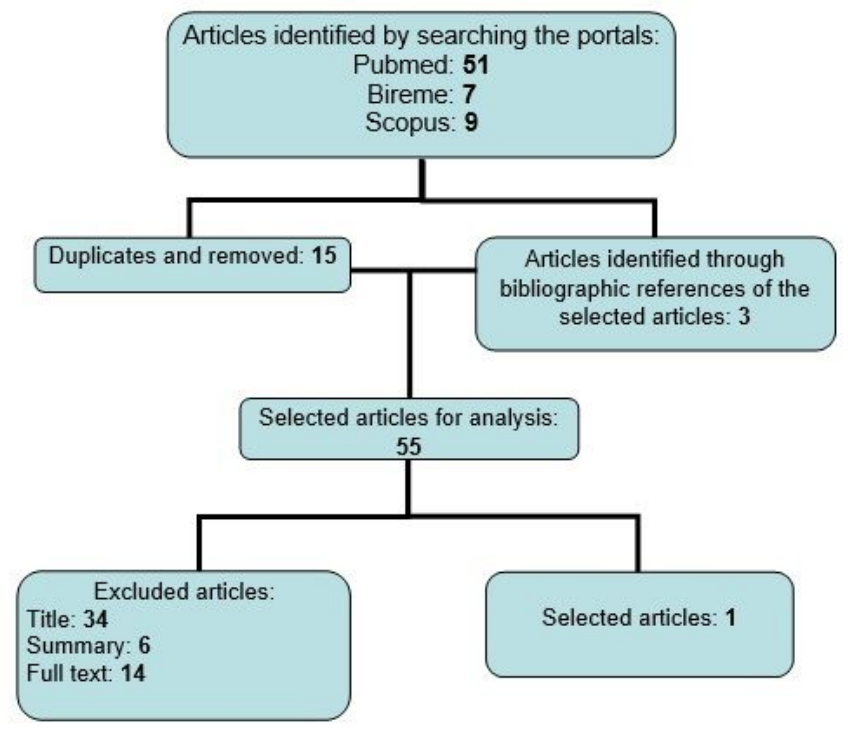

Figure 1

Flow diagram of the selection and inclusion of articles

\section{Supplementary Files}

This is a list of supplementary files associated with this preprint. Click to download.

- Table21.doc

- Table11.doc 